\title{
Article \\ The Effect of Humidity on the Electrical Resistance of Smart Sensor Based on Carbon Fibers
}

\author{
Marcin Górski 1,* , Rafał Krzywon ${ }^{2}$ and Sofija Kekez ${ }^{3}$ \\ 1 Silesian University of Technology; marcin.gorski@polsl.pl \\ 2 Silesian University of Technology; rafal.krzywon@polsl.pl \\ 3 Silesian University of Technology; sofija.kekez@polsl.pl \\ * Correspondence: marcin.gorski@polsl.pl; Tel.: +48-608-018-778
}

Received: date; Accepted: date; Published: date

Featured Application: Described smart sensor can be used as an element of externally bonded FRP strengthening system of structures. Its use in key localizations will allow monitoring stress state while maintaining strengthening properties of carbon fibers.

\begin{abstract}
The paper describes preliminary studies on the influence of humidity on the electrical resistance of a textile sensor made of carbon fibers. The concept of the sensor refers to externally bonded fiber reinforcement commonly used to strengthen building structures. However, the zig-zag arrangement of carbon fiber tow allows measuring strains, as it is done in popular resistive strain gauges. The sensor tests proved its effectiveness in the measurement of strains, but also showed a high sensitivity to changes in the temperature and humidity which unfavorably affects the readings and their interpretation. The influence of these factors must be compensated. Due to the size of the sensor, there is not possible electrical compensation by the combining of several sensors into the half or full Wheatstone bridge circuit. Only mathematical compensation based on known humidity resistance functions is possible. The described research is the first step to develop such relations. The tests were carried out at temperatures of $10{ }^{\circ} \mathrm{C}, 20^{\circ} \mathrm{C}$ and $30{ }^{\circ} \mathrm{C}$, with changing the humidity in the range of $30-90 \%$.
\end{abstract}

Keywords: textile sensor; carbon fiber; false strain compensation

\section{Introduction}

\subsection{Strain Gauge Errors and Compensation}

In laboratory conditions, it is possible to control temperature and humidity, and the sensors are treated with due care. The situation is completely different in field applications when the ability to control the sensor is limited, and exposure to the periodic impact of environmental factors, or even accidental damage is a natural risk. There is no doubt, that strain gauge after installation must be protected against mechanical, physical and chemical impacts. Absolute protection is possible by hermetic sealing. However, this method can be easily applied to relatively small, industrial sensors. In construction engineering, the sensor is often part of the structure. Examples are Fiber Optic Sensors (FOS) [1, 2] based on Bragg Grating (FBG) or Carbon Fiber Sensing [3]. Reading zone of such devices covers a large area. In such cases, an additional thick hermetic layer may be too expensive. Besides, due to its stiffness, it could also disturb the value of deformation measurement. For these reasons, the practical application of sensors requires the recognition of their characteristics under different operating conditions and the development of error compensation methods.

Between the potential sources of strain gauge errors are:

- the apparent strain caused by temperature variation [4, 5], including heating caused by excitation voltage [6], 
- $\quad$ gauge factor variation [7],

- $\quad$ moisture and humidity effects [7, 8],

- $\quad$ lead wire effects [9],

- $\quad$ transverse strain sensitivity [5].

The sensitivity of the strain sensor to temperature and humidity found during the first tests [10] lead the authors to conduct a broader study of the influence of these factors. The paper will discuss their first part concerning the effect of humidity on the measured resistance value.

\subsection{Strain Sensor Based on Carbon Fibers}

Strengthening of concrete with the use of externally bonded overlays based on high strength fibers is currently the easiest, fastest and very effective method of increasing the load-bearing capacity of building structures. Fiber reinforced composites, regardless of their superb strength to weight ratio, high specific stiffness, and significant chemical adhesion, they also have drawbacks, among which must be mentioned brittleness, unknown durability, stress rupture and in case of some fibers and resins sensitivity to certain environmental factors. The most popular carbon fibers have one more feature - they are electric conductors. The authors of this paper used this feature for the construction of a self-monitoring structural strengthening. Tests carried out on reinforced concrete, and timber beams confirmed the effectiveness of strengthening the structure (comparable to one layer of laminated carbon mat) and the simultaneous ability to measure strains in the strengthened zone [3].

Actually tested, the third generation of sensor consists of wiggly lead continuous carbon fiber thread (zig-zag pattern typical for the majority of strain gauges). The thread is stabilized by fastening to the composite mesh matrix commonly used as a plaster reinforcement (Fig. 1). Compared to the previously developed woven modifications [11], this construction allows the creation of a sensor of any length under conditions of building side. Glass fiber mesh stabilization reduces the risk of accidental short-circuiting during the assembly of the sensor. There is no need for additional separating acrylic threads. The parallel alignment of the carbon tow multiplies the length of the measuring base and thus improves the accuracy of the measurement.

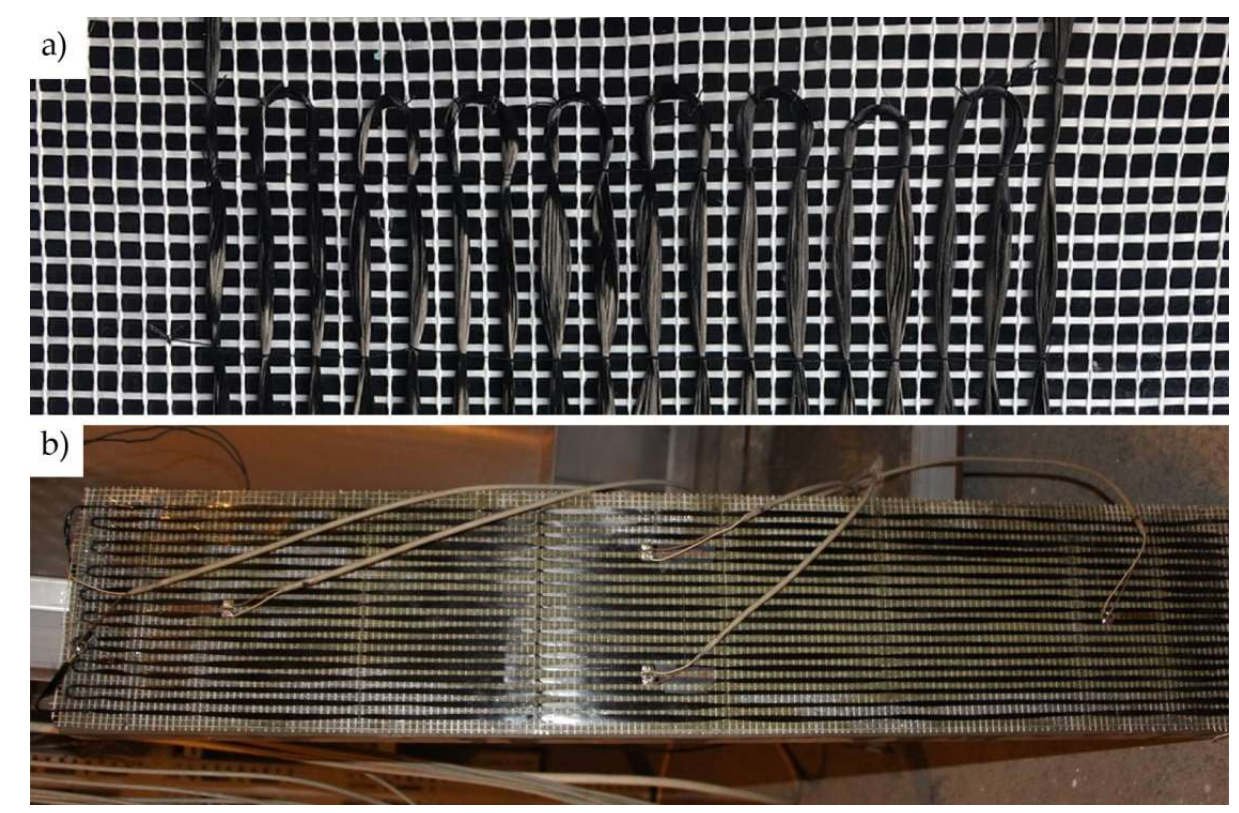

Figure 1. The third generation of textile sensor: (a) Carbon fiber tow fixed to the composite mesh; (b) Ready sensor laminated on the concrete specimen. 


\subsection{Effect of moisture and humidity on the gauge resistance}

The construction of foil strain gauges assures relatively good resistance to the risk of errors associated with changes of humidity. The dominant view is that the effect of humidity should be concerned when long term measurement is planned, or environmental conditions may be unfavorable [5]. The influence of humidity usually results from ingress of moisture and chance current flow between wires, what changes the nominal resistance of the gauge. Other factors may be related to corrosion, changes in the local properties of materials [12], degradation of backing. Undoubtedly, the size of the sensor may influence the humidity error.

Development of self-sensing textiles for construction engineering is nowadays based mainly on the optical systems. Self-sensing fibers are in the initial stage of the research which mainly focuses on the short fibers dispersed in the matrix [13]. In the case of a textile sensor based on continuous fibers, some references can only be found in the studies on the humidity effects on the performance of temperature sensing fabric. Such researches $[14,15]$ show the relatively high sensitivity of textile sensors to relative humidity $\mathrm{RH}$. The relative increase of resistance at the level of $20 \%$ is unacceptable when measuring a deformation of building structures. In the case of the developed textile sensor, this unfavorable phenomenon should improve the encapsulation of carbon fibers in the epoxy resin after the lamination process. Cured epoxies have dielectric properties. Thanks to that they are used for coating and encapsulating electrical circuits. Dielectric permittivity of epoxy resins is around $3 \div 6$, their dielectric strength $120 \div 180 \mathrm{kV} / \mathrm{mm}$ and the volume resistivity $10^{19} \div 10^{12} \Omega / \mathrm{m}[16]$. Such a characteristic allows the movement of electrons along the carbon fibers. However, they can also be transmitted between the adjacent fibers. Transverse conductivity, in this case, depends mainly on the distance between the fibers, but could also be influenced by the shape or pre-treatment of fibers [17]. The transport of electron across an insulator gap is referred to as tunneling. This process is sensitive to the gap width and height of the potential barrier to be penetrated [17].

Dielectric properties of epoxies can be degraded due to their permeability and absorption of water [16]. The absorbed water can promote electrolytic conducting between parallel bundles of carbon fibers, thus changing the resistance of the sensor. The aim of the research described in the further part of the paper is first of all to determine the scale of this phenomenon and possible consequences for the gauge error.

\section{Materials and Methods}

\subsection{Test equipment}

The following test equipment has been used during the test:

- A UNI-MORS Climatic Chamber (LM 14/2012) with internal dimensions of $1.5 \times 0.6 \times 0.5 \mathrm{~m}$, allowing temperature changes in the range of -30 to $+90^{\circ} \mathrm{C}$ and $\mathrm{RH}$ in the range of $20 \%$ to $95 \%$.

- 64 channel Wheatstone bridge Z-TECH.

- Reference, foil strain gauges type PFL-30-11 (Tokyo Sokki Kenkyujo Co.), 30 mm long, gauge factor 2.13, gauge resistance $120 \pm 0.3 \Omega$.

\subsection{Preparation of the test sample}

After attaching the carbon fibers to the glass fiber mesh, the ready sensor was adhered to the concrete prism with dimensions of $1000 \times 200 \times 60 \mathrm{~mm}$. Two-component epoxy S\&P Resin 55HP was used for this purpose. This specific adhesive is intended for fixing carbon sheets to various types of substrate. Wet lay-up technology was applied. First, the substrate was impregnated, then the sensor was placed, the carbon fibers were aligned and saturated with resin. The adhesive layer was leveled with a roller.

A single thread of conductive carbon fiber was delivered by the FISIPE Synthetic Fiber Company. The rowing consists of 24000 filaments (1600 tex). The tensile strength of carbon fiber is equal to $5000 \mathrm{MPa}$, modulus of elasticity $270 \mathrm{GPa}$ and an ultimate elongation at break 1,9\%. 
Filament resistivity is equal to $14 \mu \Omega \mathrm{m}$. The sensor has a length of 1 meter, contains 18 parallel threads, its initial resistance, measured at the beginning of the test was equal to $254 \Omega$.

On the surface of the sample, reference foil gauges were adhered in the arrangement shown in Figure 3. The reference gauges were placed both the side of the textile sensor and on the rear side, on the concrete surface.

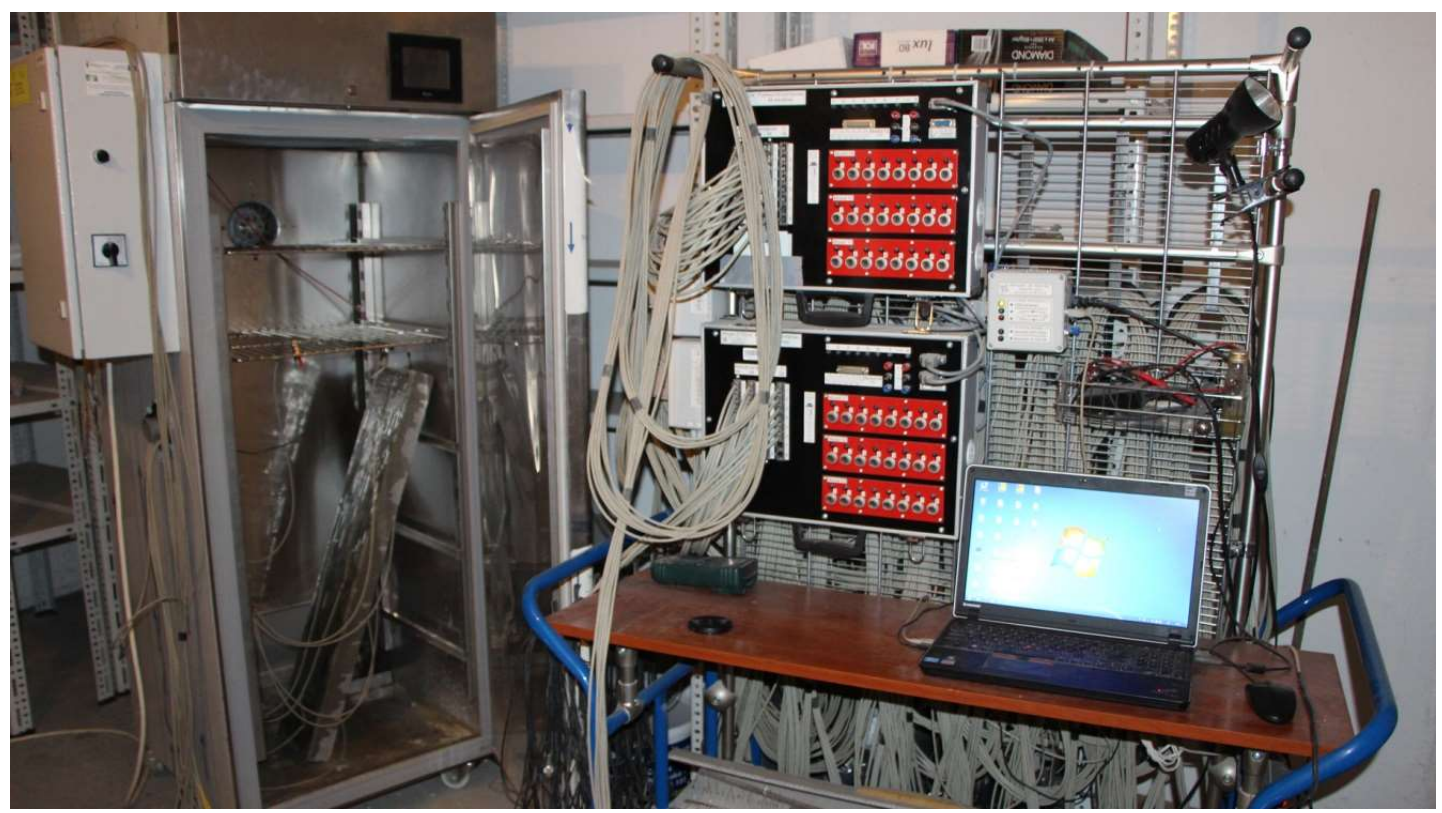

Figure 2. Test equipment.

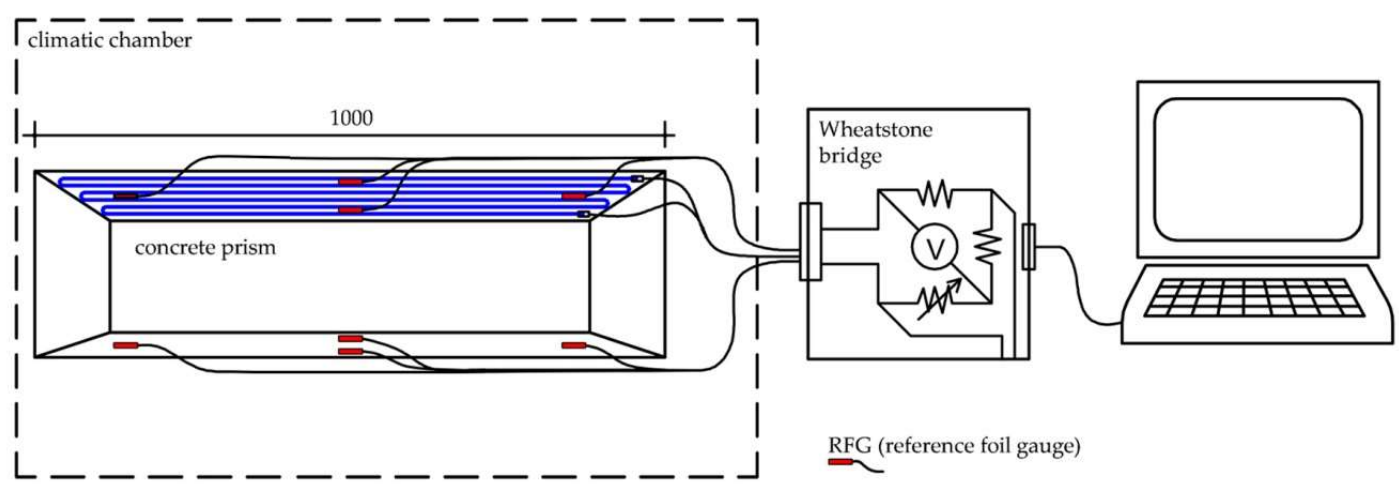

Figure 3. Experimental set-up.

\subsection{Test procedure}

To allow the samples to reach equilibrium with the climatic environment, before the beginning of the test they were kept inside the climatic chamber for a minimum of 12 hours.

After placing in the climatic chamber, a control measurement was carried using a simple ohmmeter to check initial resistance and to exclude accidental short circuit. Then the textile sensor was connected to the Wheatstone bridge, the chamber was closed, and the test started.

During the test, the actual humidity was saved by the chamber controller and at the same time resistance changes expressed by apparent strains were recorded every 60 seconds through a computer connected to the Wheatstone bridge.

An isothermal experimental cycle was applied, in which the temperature was kept constant, while the relative humidity $(\mathrm{RH})$ was varied between the $30 \%$ and $90 \%$. Two types of such cycles were provided: 
- $\quad$ stabilization of temperature and humidity at $60 \%$, its increase to $90 \%$ and minimum 1 -hour break for the stabilization of readings, decrease of humidity to $60 \%$ and 1 hour pause, then continue to reduce humidity by up to $30 \%$ and another pause to stabilize the measurement, return to the humidity of $60 \%$,

- $\quad$ stabilization of temperature and humidity at $60 \%$, its increase to $70 \%$ and minimum 20 minutes break and such an incremental increase up to $90 \%$, then gradually reduce the humidity by $10 \%$ with breaks of 20 minutes, up to $30 \%$, and similar return to a humidity of $60 \%$.

Each described above cycle procedure was repeated at a constant temperature of $+10{ }^{\circ} \mathrm{C},+20{ }^{\circ} \mathrm{C}$ and $+30{ }^{\circ} \mathrm{C}$.

\section{Results and Discussion}

The test results for cycles with rapid change in relative humidity are shown in separate graphs (Fig. $4 \div 9$ ). The chamber control system does not allow to determine the rate of humidity change, besides, change in resistance appeared with a certain delay to humidity. To demonstrate this phenomenon, the graphs are shown as a function of time and supplemented with the characteristics of humidity changes. The graphs also show averaged measurements made with the use of reference foil gauges placed on both sides of the sample. To estimate the magnitude of the error, resistance changes are shown in strain units calculated in accordance with specific gauge factors. This reflects the assessment of the error concerning the underestimated or overrated value of stresses. For example, for an average carbon fiber with a modulus of elasticity of approximately $190 \mathrm{GPa}$ and a strength of $2500 \mathrm{MPa}$, the strain of $1 \%$ means an error of $7 \%$ strength and even about $15 \%$ of the strain at which delamination failure may occur.

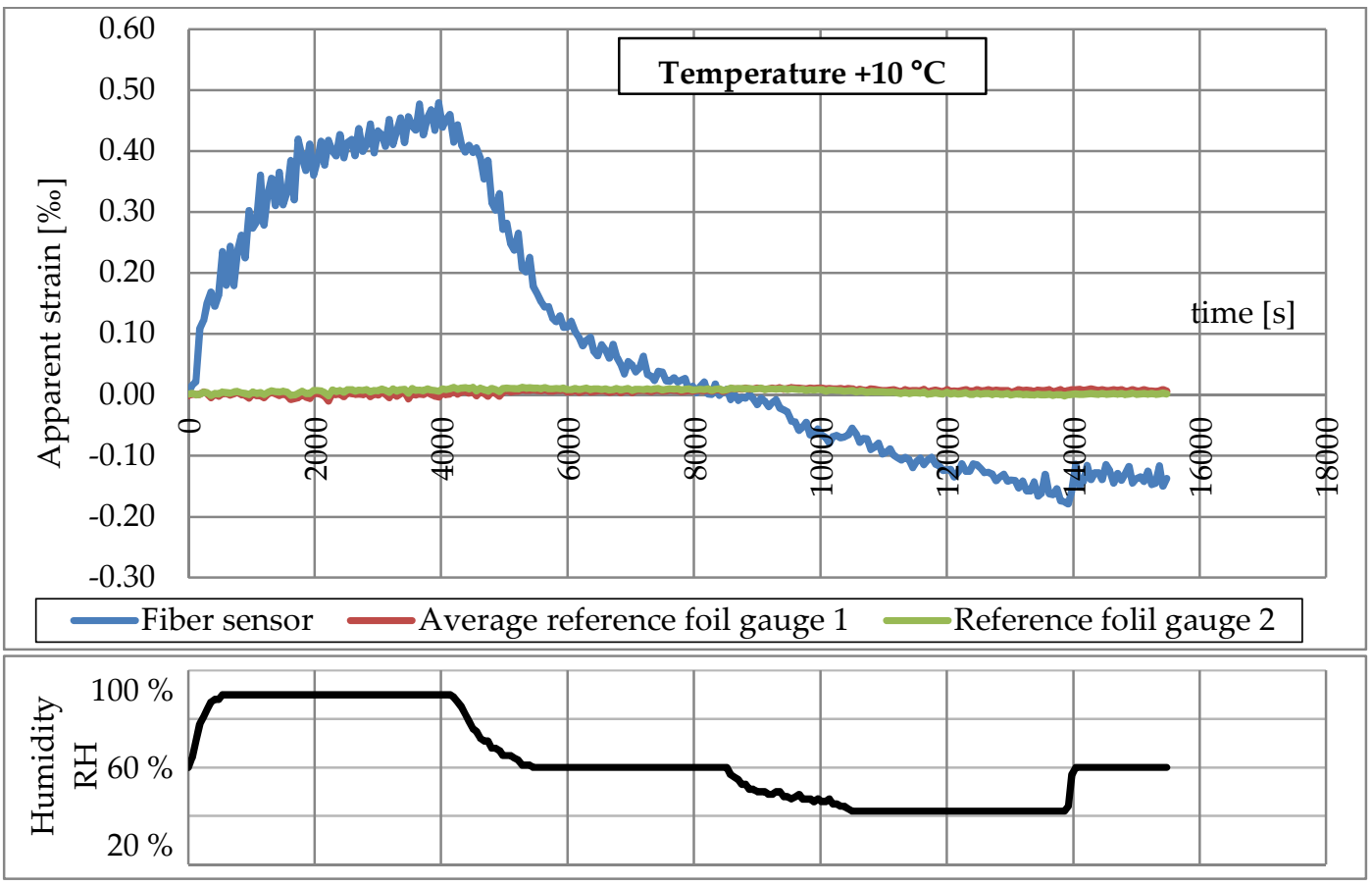

Figure 4. Change of apparent strain in the cycle at $10^{\circ} \mathrm{C}$. 
4 of 10

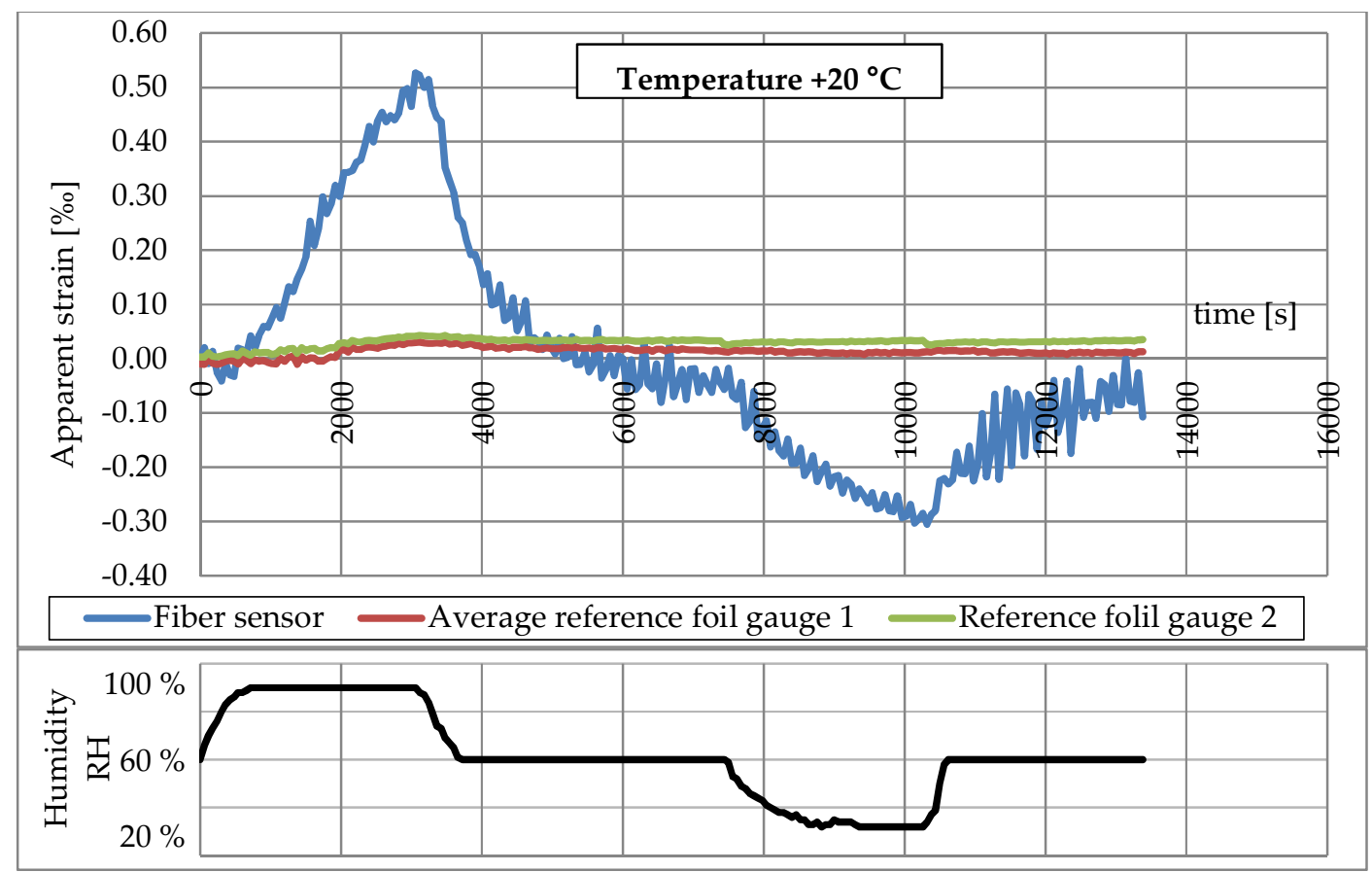

Figure 5. Change of apparent strain in the cycle at $20^{\circ} \mathrm{C}$.

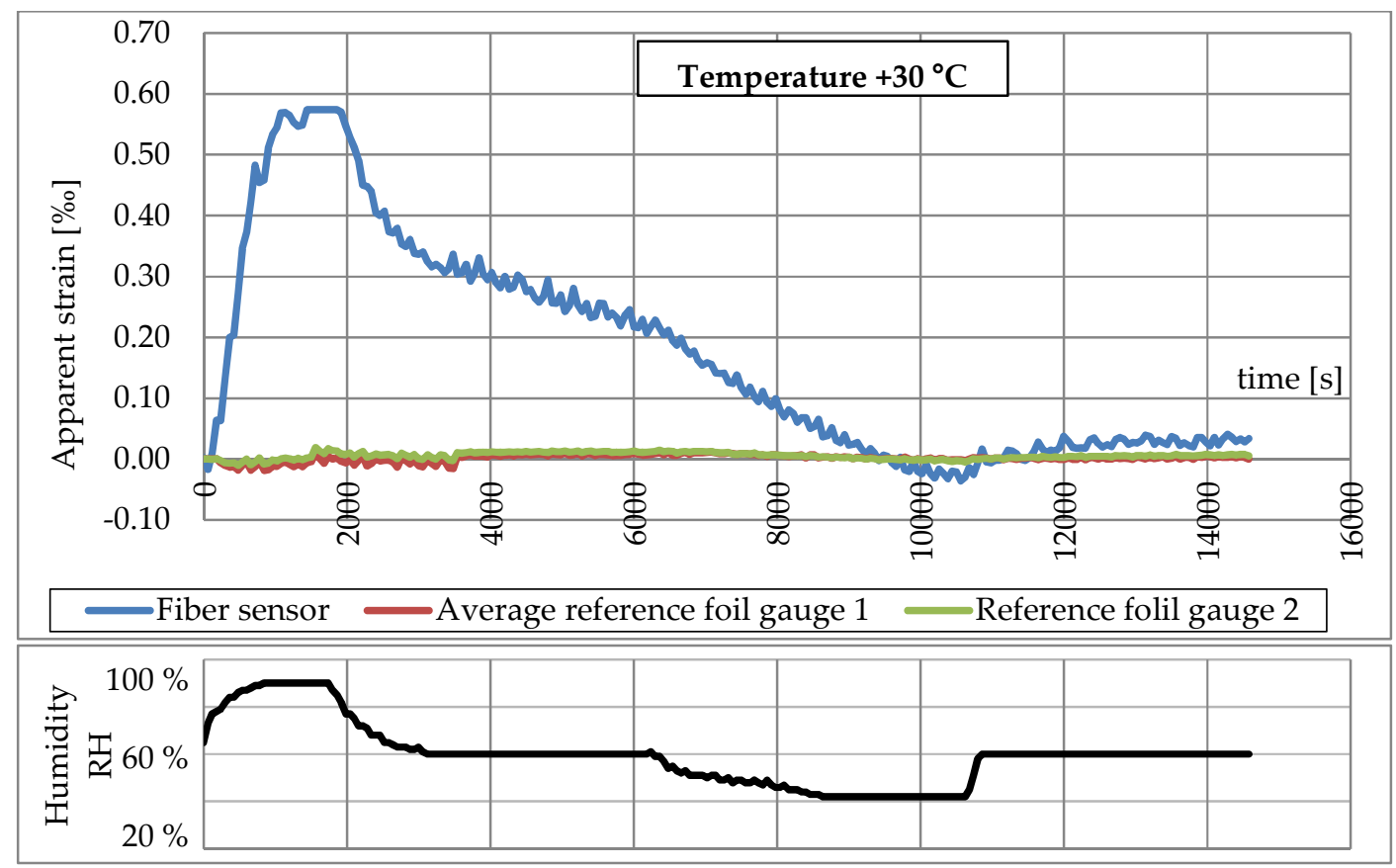

Figure 6. Change of apparent strain in the cycle at $30^{\circ} \mathrm{C}$.

The following graphs (Fig. $7 \div 9$ ) show the change in the stress in the cycles of gradual variation of relative humidity. As in the previous graphs, the process of humidity changes during the test is shown below each graph. 
5 of 10

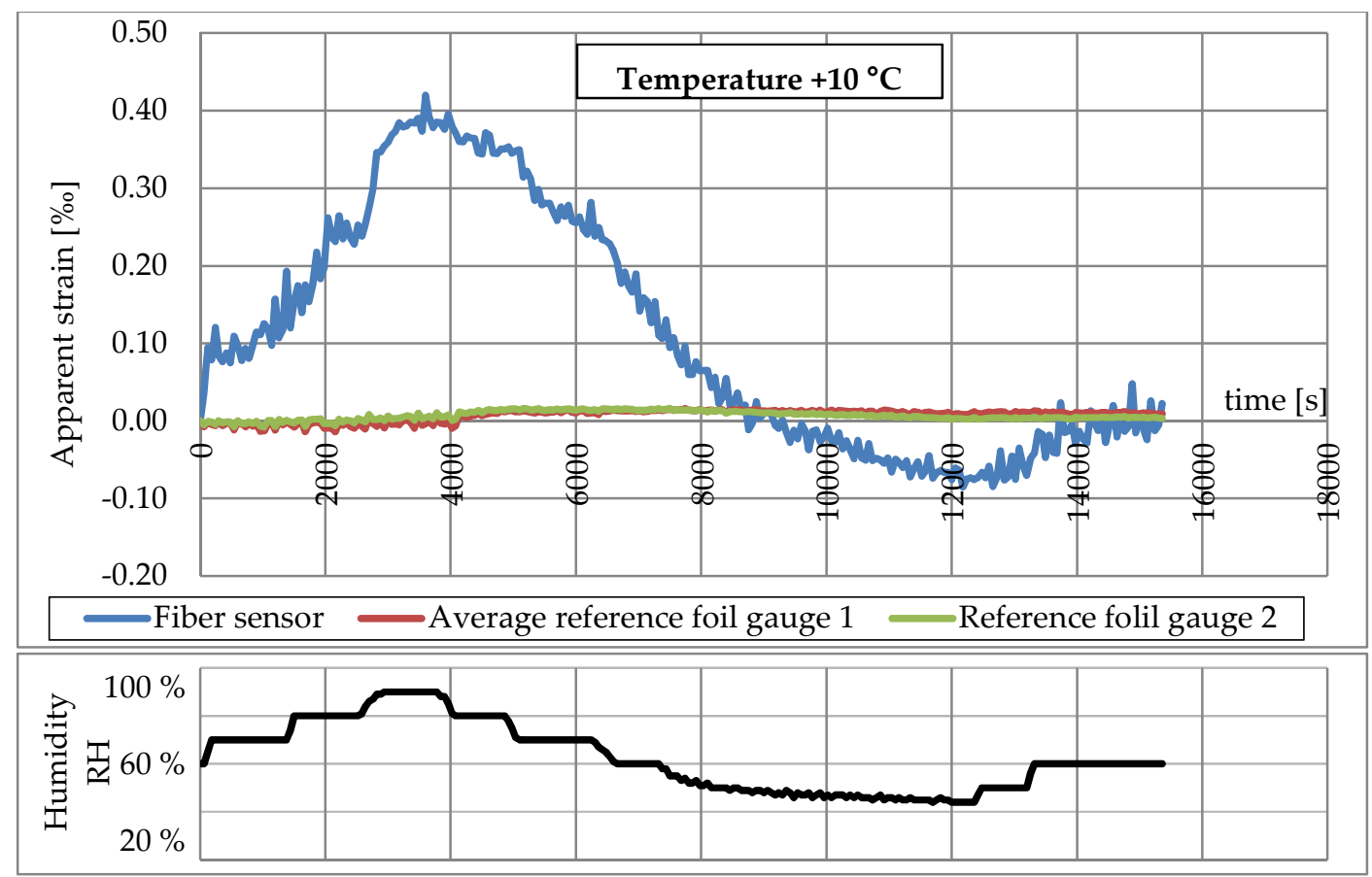

Figure 7. Change of apparent strain in the cycle of gradual variation of $\mathrm{RH}$ at $10^{\circ} \mathrm{C}$.

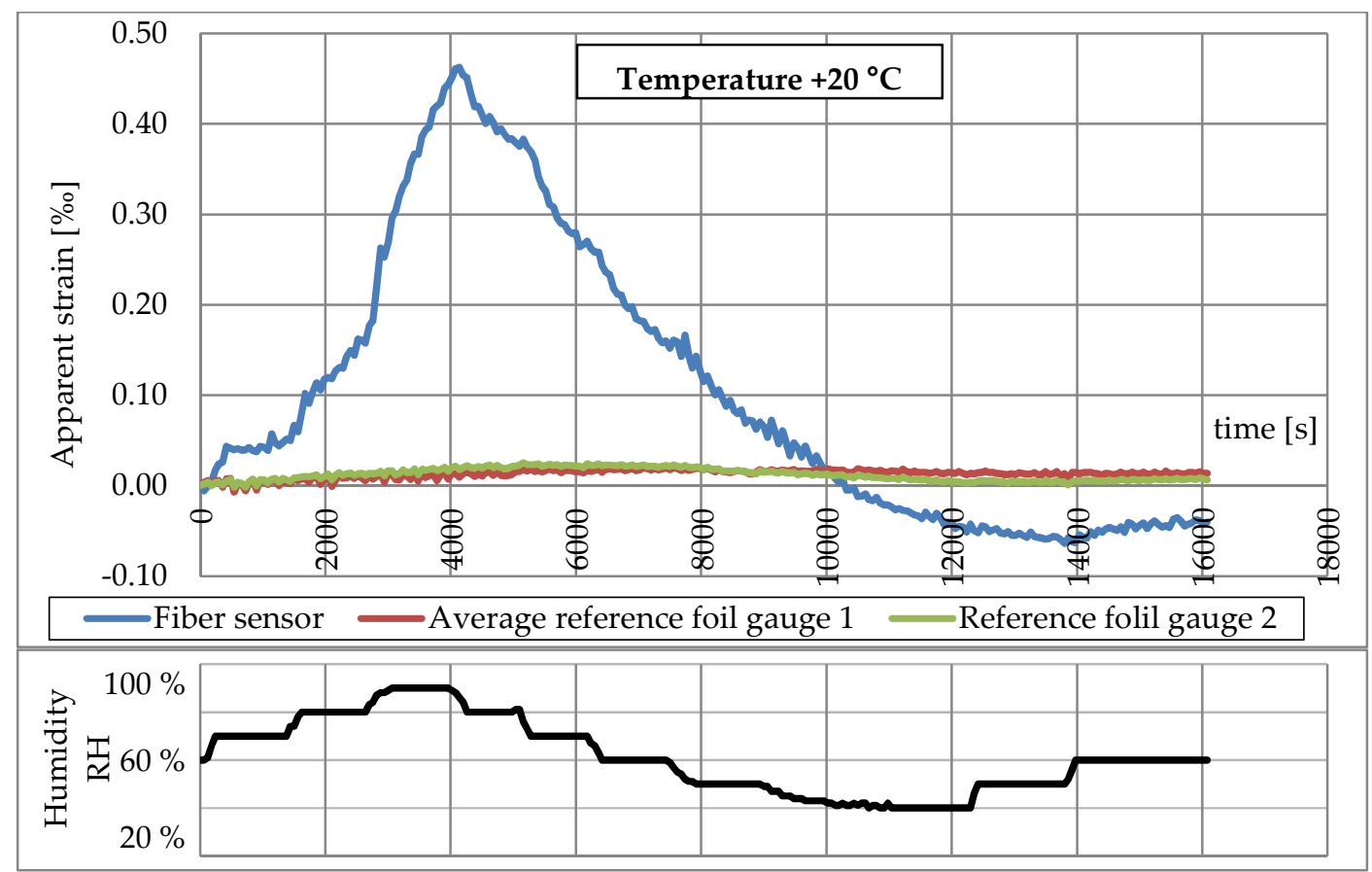

Figure 8. Change of apparent strain in the cycle of gradual variation of $\mathrm{RH}$ at $20^{\circ} \mathrm{C}$. 
6 of 10

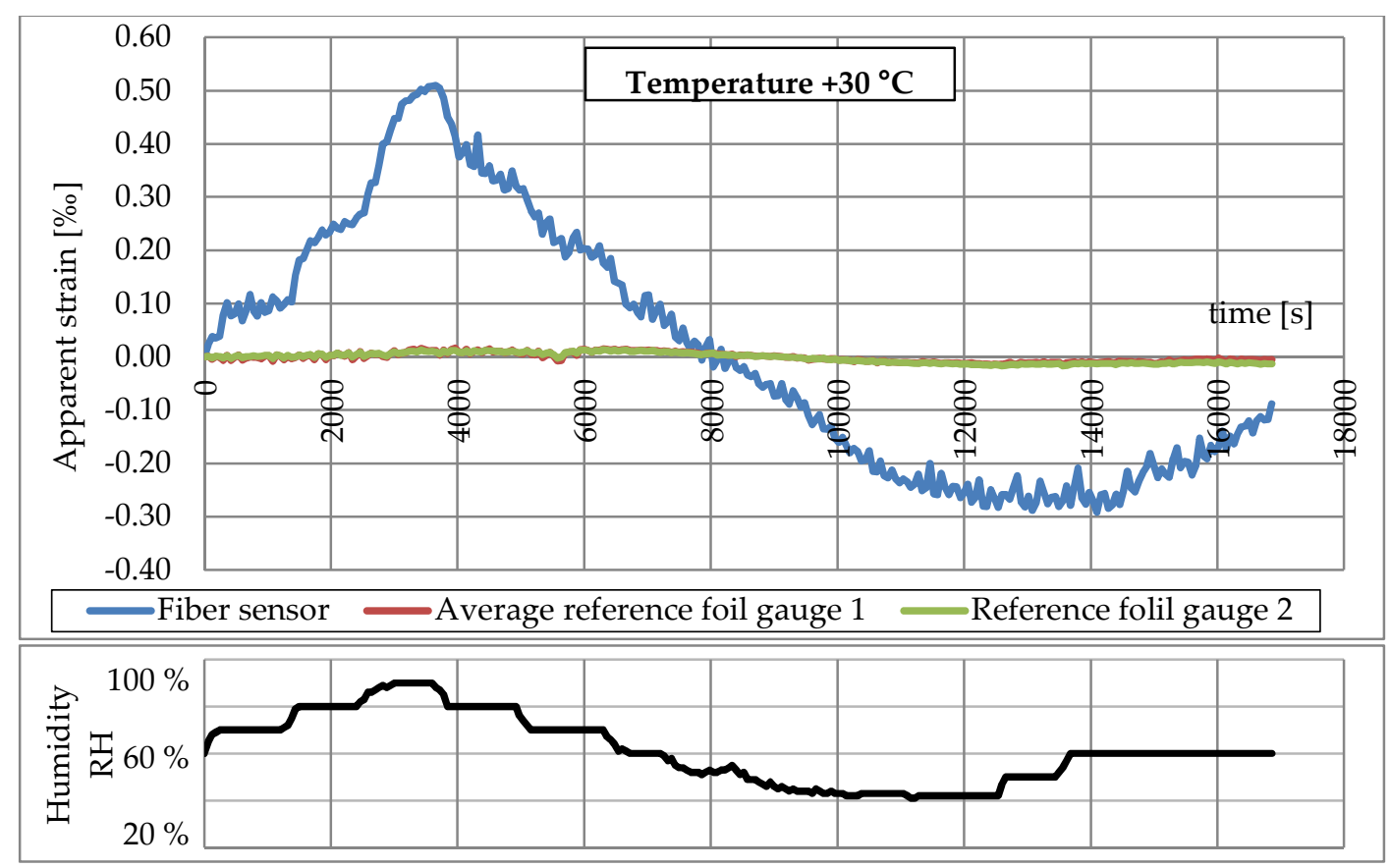

Figure 9. Change of apparent strain in the cycle of gradual variation of $\mathrm{RH}$ at $30^{\circ} \mathrm{C}$.

From the presented results, the following statements can be formulated:

- The largest recorded error in the form of apparent strain is almost $0.6 \%$ (Fig. 6). In the diagnostics of CFRP composites, this means an error of around 5\% of carbon fiber strength and $10 \%$ of strain, which often causes the failure due to delamination. These are significant values, especially for one source of gauge error.

- The gauge error is higher in a humid environment than in a dry environment, what indicates the moistening as the primary source of resistance changes.

- In higher humidity, especially above $\mathrm{RH} 80 \%$, the resistance decrease is more intense, which may result from the growing penetration of moisture into the structure of epoxy matrix and the formation of electrolytic solutions therein.

- At higher temperatures, the effect of humidity increases, the difference for temperatures +10 and $+30{ }^{\circ} \mathrm{C}$ is relatively $35 \%$. The probable reason for this phenomenon may be increasing absolute humidity at higher temperatures or change in permeability of epoxides.

- The change in resistance is delayed to the change in humidity. For an immediate change in humidity, the resistance stabilizes after at least one hour, although the time required for stabilizing the measurement depends on the scale of the humidity change. The probable cause of the delay is the long-term process of moisture exchange between the composite and the air.

- Due to the delay described above, the measurement at the end of the cycle, at $60 \%$ humidity, does not return entirely to the zero point.

- At a similar rate of humidity change, the resistance decrease (indicated as an increase of apparent strain) is faster than its increase. The causes that the function of apparent strain vs relative humidity has a different course for the process of humidity rise and its decrease (Fig. 10). This means that a mathematical description of this change would also have to contain information about the direction of humidity changes. The analysis of the position of the functions in Figure 10 also shows that the position of the cycle curves is the most similar at $30^{\circ} \mathrm{C}$. The cause may be a slightly easier moisture exchange at a higher temperature, especially more intensive drying. 


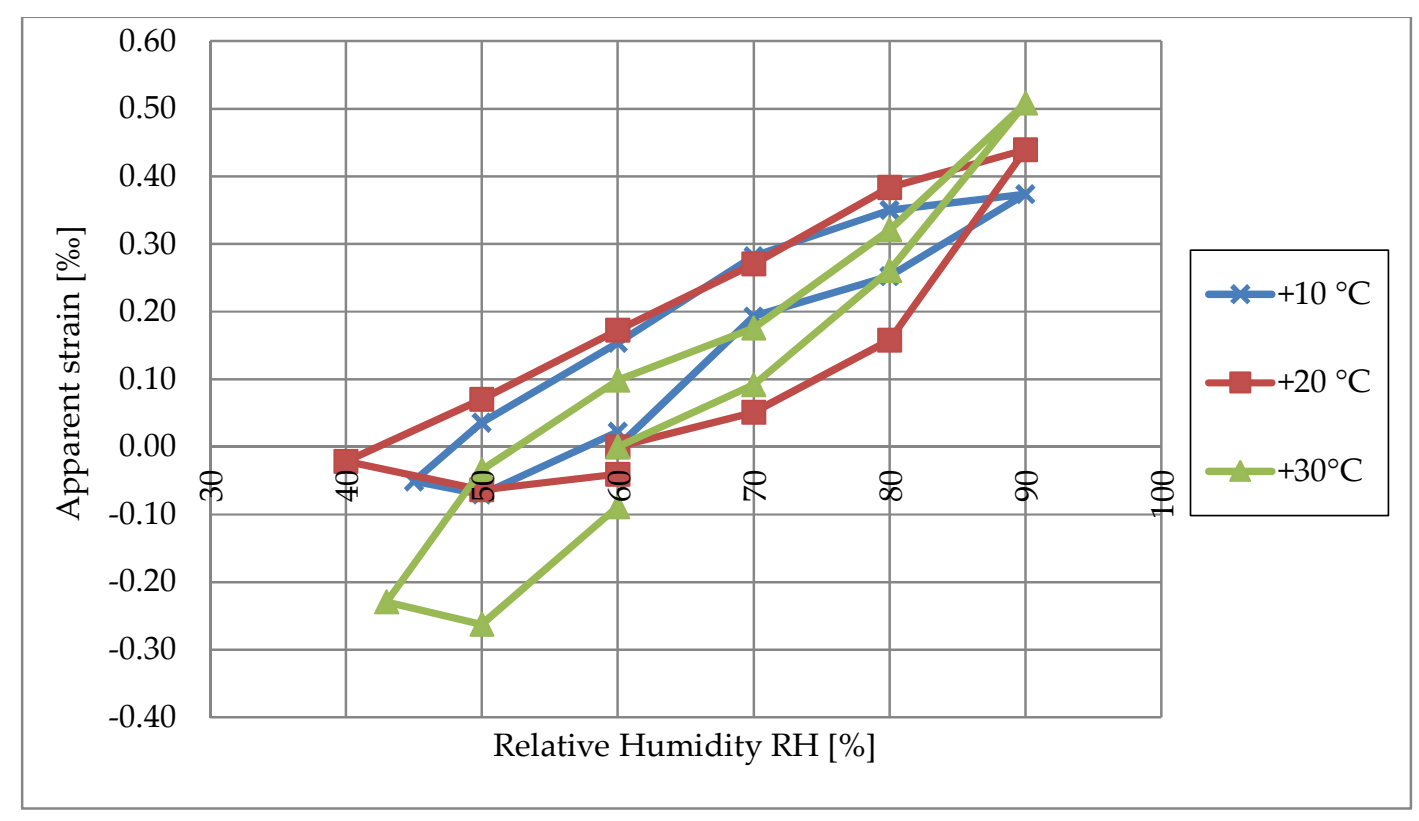

Figure 10. Apparent strain vs relative humidity for cycles at $10^{\circ} \mathrm{C}, 20^{\circ} \mathrm{C}$ and $30^{\circ} \mathrm{C}$.

\section{Conclusions}

The test results show that relative humidity significantly affects the measurement of deformations using a developed textile sensor. Reading error can be over twenty times higher than when using traditional plastic strain gauges.

The sensor is particularly sensitive to the relative humidity increase in the range of $60 \div 90 \%$. Changes in resistance in a dry environment, for $\mathrm{RH}$ below $60 \%$ are several times smaller. Such properties clearly show that the reason for the changes in resistance is too large permeability of the epoxy resin and its moistening in the humid environment.

There could be noticed a delay in resistance changes in relation to relative humidity changes. This phenomenon refers more to the process of reducing humidity, which may mean a faster process of moistening the epoxy matrix than drying it.

The gauge error found during the tests in a humid environment is unacceptable in practical applications. Due to the delay in resistance changes, the mathematical calibration of the measurement may be unreliable, especially in the case of rapid changes in humidity (e.g. the following rain and drying with the sun activity). A useful improvement can be the application of a thin, impermeable protective layer on the surface of the sensor. Research on the implementation of such a layer will be the next step in the development of a textile sensor for simultaneous monitoring and reinforcement of the structure.

Author Contributions: Conceptualization, R.K. and M.G.; methodology, R.K.; validation M.G. and R.K.; formal analysis, M.G; investigation, S.K.; resources, R.K.; data curation, S.K.; writing-original draft preparation, R.K. and M.G.; writing-review and editing, R.K. and M.G.; visualization, R.K.; supervision, M.G.; project administration, M.G.; funding acquisition, M.G.

Funding: This research was funded by Silesian University of Technology grant number BK237/RB6/2018.

Acknowledgments: The authors acknowledge the European Union for financing the development of intelligent textile sensor (Project 251373 FP7-PEOPLE-2009-IAPP-Intelligent Systems for Structures Strengthening and Monitoring INSYSM) and the Silesian University of Technology (Grant no BK-237/RB6/2018) for financing of current research. Authors also acknowledge FISIPE Synthetic Fiber SA, Portugal and S\&P Reinforcement Poland for the supply of carbon fibers.

Conflicts of Interest: The authors declare no conflict of interest. The funders had no role in the design of the study; in the collection, analyses, or interpretation of data; in the writing of the manuscript, and in the decision to publish the results. 
8 of 10

\section{References}

1. Luyckx, G.; Voet, E.; Lammens, N.; Degrieck, J. Strain measurements of composite laminates with embedded fibre Bragg gratings: Criticism and opportunities for research. Sensors 2010, 11, 384-408.

2. Sieńko, R.; Zych, M.; Bednarski, Ł.; Howiacki, T. Strain and crack analysis within concrete members using distributed fibre optic sensors. Structural Health Monitoring 2018 (in press).

3. Krzywon, R.; Gorski, M.; Dawczynski, S.; Szojda, L.; Castro Gomes, J.; Salvado, R. Self-Monitoring Strengthening System Based on Carbon Fiber Laminate. Journal of Sensors 2016, 1-8.

4. Hall, M.P.; Deighan A.R. On Using Strain gauges in Electronic Assemblies When Temperature is Not Constant. IEEE Transactions on Components, Hybrids, and Manufacturing Technology 1986, 9(9), 492-497.

5. ISIS CANADA. Guidelines for Structural Health Monitoring, Design Manual No.2, 2001, pp. A1-A17.

6. Zhang, T.; Evans, R.G.R.; Rees W.A.D. The heating effect of electrical resistance strain gauges applied to low thermal conductivity materials, Strain 1992, 107-112.

7. Akhtar K.S.; Xinwei W. Strain Measurements and Stress Analysis, Publisher: Pearson, USA, 2000, p. 272.

8. Perry, C.C.; Lissner, H.R. The Strain Gauge Primer, Publisher: McGraw-Hill, USA, 1955, p. 281.

9. Koch, J.J.; Boiten, G.R.; Biermasz, L.A.; Roszbach, P.G., Van Santen, W.G. Strain Gauges Theory and Applications, Publisher: Philips Technical Library 1952.

10. Górski, M.; Krzywoń, R.; Borodeńko, M. Development of self-sensing textile strengthening system based on high-strength carbon fiber. Materials 2018, 11(10), 2062.

11. Salvado, R.; Lopes, K.; Szojda, L.; Araujo, P.; Gorski, M.; Jose Velez, F.; Castro Gomes, J.; Krzywon, R. Carbon Fiber Epoxy Composites for Both Strengthening and Health Monitoring of Structures. Sensors 2015, 15(5).

12. Stockmann, M.; Naumann, J.; Ihlemann J. 25 Years Basic Research in The Field of Strain Gage Technology on Chemnitz University of Technology - Institute of Mechanics, Proceedings of the 34th Danubia-Adria Symposium on Advances in Experimental Mechanics, University of Trieste, Italy, 2017.

13. Rana, S.; Subramani, P.; Fangueiro, R.; Correia, A.G. A review on smart self-sensing composite materials for civil engineering applications. AIMS Materials Science 2016, 3(2), 357-379.

14. Cochrane, C.; Koncar, V.; Lewandowski, M.; Dufour C. Design and Development of a Flexible Strain Sensor for Textile Structures Based on a Conductive Polymer Composite, Sensors 2007, 7, 473-492.

15. Husain, M.D.; Atalay, O.; Kennon, R. Effect of Strain and Humidity on the Performance of Temperature Sensing Fabric. International Journal of Textile Science 2013, 2(4), 105-112.

16. Johari, G.P. Electrical properties of epoxy resins. Chemistry and Technology of Epoxy Resins, 2nd ed.; Bryan E, Eds.; Publisher: Chapman \& Hall, USA, 1993; pp. 175-205.

17. Sancaktar, E.; Bai, L. Electrically Conductive Epoxy Adhesives, Polymers 2011, 3, 427-466. 